\title{
Inhibition of ZAR1 Enhances Cancer Cell Proliferation on Non- smoking Lung Cancer Patients
}

\author{
Jana Choe \\ The Governor's Academy, 1 Elm St, Byfield, MA 01922, 01922, USA; gosyber@suwon.ac.kr
}

ABSTRACT: Tobacco smoking has long been highlighted as the main cause for lung cancer. However, many cases of lung cancer have also been reported in nonsmokers. Air pollution, chemical exposure, mutations, and other genetic alterations are known to be associated with lung cancer. This research focuses on genetic alterations of lung cancer patients who have never smoked in their lifetime. Using cBioportal, genomic alterations of a total of 1144 patients (111 Lifelong non-smokers and 976 smokers) were analyzed in this study. It was found that lifelong non-smoking patients have a much higher rate of deletion on Chromosome 4 (cytoband position 4p11) compared to that of the smoking patients. Among the 8 genes that are located on $4 \mathrm{p} 11$, this research mainly focused on Zygote Arrest 1 (ZAR1) gene because there is a recent discovery of guiding evidence that suggests a potential interconnection between ZAR1 and cancer. To understand the role of ZAR1 on cell proliferation in lung cancer, mRNA expression of ZAR1 was inhibited using small interference RNA (siRNA). When ZAR1 mRNA was depleted, cancer cell proliferation increased in the NCI-H358 cell line. In conclusion, ZAR1 depletion increases cancer cell proliferation, and it can be used as a biomarker for lifelong non-smoker lung cancer.

KEYWORDS: Cellular and Molecular Biology; Molecular Biology; Lung Cancer; ZAR1; Non-smoker.

\section{- Introduction}

Lung cancer is by far the leading cause of cancer related deaths worldwide, accounting for approximately 25 percent of all cancer deaths. ${ }^{1}$ Being the leading cause of cancer deaths in men and the second leading cause in women, lung cancer is characterized by a poor five year survival rate of $18.6 \%{ }^{2}$ The two main types of lung cancer are small cell (Small cell lung cancer tends to be more aggressive than the non-small cell cancer) and non-small cell lung cancer, distinguished by the size and characteristics of the cancerous cells. ${ }^{3}$

Tobacco-smoking is believed to be the main cause of lung cancer. However, other causes of lung cancer have been studied by the researchers. ${ }^{4}$ Although smokers are more vulnerable to cancer cell developments, lifelong non-smokers can also develop cancer cells. The research of genetic alterations on lung cancer from nonsmokers is very limited. ${ }^{5}$ To find the novel genetic alterations in lung cancer from nonsmokers, the gene alteration found mainly in non-smokers from data provided in the cBioportal was analyzed. ${ }^{6}$ By analyzing genetic alterations in 1144 patients, it was observed that Human zygote arrest 1 (ZAR1) is one of the genes that is frequently deleted in lifelong non-smokers' lung cancer cells.

ZAR1 is located on chromosome 4 (4p11). ZAR1 is found to have a critical effect on oocyte-to-embryo transition. ${ }^{7}$ It is inactivated during the development of the embryo; however, ZAR1 is a maternal gene whose products (RNA or protein) are produced by the oocyte before the embryo development. ZAR1 is found to be mainly expressed in human lungs. ${ }^{8}$ Growing evidence points to the possible correlation between the role of ZAR1 and cancer. ZAR1 has recently been brought back to the surface when researchers observed that ZAR1 was inactivated in lung cancer cell lines. ${ }^{8}$ It is now suspected to be a potential tumor suppressor gene. ${ }^{8}$ To further clarify this correlation, this study investigated whether ZAR1 is a potential tumor suppressor that may affect the development of cancer cells. In order to find the relationship between the deletion of ZAR1 and development of lung cancer, ZAR1 was depleted by siRNA and its subsequent effect on cancer cell proliferation was analyzed.

\section{Methods \\ Cell culture :}

NCI-H358 cells were purchased from Korea Cell Line Bank. Cells were routinely cultured in RPMI 1640 medium (Gibco) supplemented with $10 \%$ inactivated FBS (Hyclone), $100 \mathrm{U} / \mathrm{mL}$ penicillin and $100 \mu \mathrm{g} / \mathrm{mL}$ streptomycin (Gibco). Cells were maintained at $37{ }^{\circ} \mathrm{C}$ in a $5 \% \mathrm{CO} 2$ humidified environment and prepared for experimental procedures when in log-phase growth.

siRNA transfection :

The small interfering RNA (siRNA) prevents the translation of specific genes with complementary nucleotide sequence, silencing their expression. The siRNA transfection is a process that enables the siRNA to be delivered to the cells. The reagent used within the process forms a complex with the siRNA, helping it to penetrate the membrane. The siRNA, when it enters the targeted cells, incorporates with other proteins to form the RNA-Induced Silencing Complex (RISC). The siRNA unwinds to form single stranded siRNA, which then binds to its complementary nucleotide and induces mRNA cleavage.

With this technique, the expression of ZAR1 of the cancer cell lines can be regulated. Four different samples are used in this study: cell line without any treatment, with $0.3 \mu \mathrm{l}$ of control siRNA, with $0.3 \mu \mathrm{l}(10 \mathrm{pmol})$ of siZAR1, and with 
$0.6 \mu \mathrm{l}(20 \mathrm{pmol})$ of siZAR1. siRNA was transfected with a transfection reagent, RNAimax (Invitrogen). The mole ratio of siRNA:reagent was prepared as 1:3. The cells were transfected with the mixed solution of siRNA and transfection reagent for $48 \mathrm{~h}$.

\section{Total RNA extraction:}

RNA extraction is a process used for the isolation of total RNA from a given sample of cell lines or tissues. RNA-spin ${ }^{\mathrm{TM}}$ Total RNA Extraction Kit to extract the macromolecules from the cell lines was used. After removing the culture media, we replaced it with a R-buffer, which helps cell lysis. We added $350 \mu \mathrm{l}$ of $70 \% \mathrm{EtOH}$ to the lysate and centrifuged the mixture in a spin column to collect the required RNA. We then purified the extracted RNA using two types of washing buffers (Washing buffer A, B) to cleanse the RNA of possible remnants and used an elution buffer to collect the total RNA.

\section{cDNA synthesis:}

cDNA was synthesized from the extracted RNA using TOPscript ${ }^{\mathrm{TM}}$ Reverse Transcriptase (Enzynomics). The cDNA reaction was prepared as follows: $5 \mu \mathrm{l}$ of extracted RNA, $1 \mu$ of oligodT ( 20 pmol), $2 \mu \mathrm{l} 10 \mathrm{x}$ reaction buffer, $1 \mu \mathrm{R}$ R enzyme, and water was added up to $20 \mu \mathrm{l}$. The cDNA synthesis was performed as follows: $25^{\circ} \mathrm{C}$ for $10 \mathrm{~min}, 42^{\circ} \mathrm{C}$ for $1 \mathrm{~h}, 95^{\circ} \mathrm{C}$ for $5 \mathrm{~min}$, and $4{ }^{\circ} \mathrm{C}$ for infinite.

\section{Polymerase Chain Reaction:}

Polymerase chain reaction (PCR) is a method used to rapidly replicate a specific DNA sample. This allows the scientist to amplify a very small amount of the sample to a larger amount for the better quality and the detail of the research. The PCR reaction was performed in stages: 1) $95.0^{\circ} \mathrm{C}$ for 5 minutes, 2) repetition of $95.0^{\circ} \mathrm{C}$ for 30 seconds, $55.0^{\circ} \mathrm{C}$ for 1 minute, and $72.0^{\circ} \mathrm{C}$ for 40 seconds for 40 times, 3) $72.0^{\circ} \mathrm{C}$ for 5 minutes, and 4) continuation in $10.0^{\circ} \mathrm{C}$.

Agarose gel electrophoresis:

Agarose gel electrophoresis separates the RNA in a matrix of agarose by length and/or size. The 1.5\% Agarose gel was prepared using $1.5 \mathrm{~g}$ of agarose mixed with $100 \mathrm{ml}$ of Tris-borate-EDTA (TBE) buffer. The mixture was microwaved for 3 minutes until agarose powder was completely dissolved in the buffer. Then, RedSafe Nucleic Acid Staining Solution (Intron) was added to the solution.

Once prepared, the caste was submerged in a buffer in an electrophoresis tank, before loading RNA samples into the pore. GAPDH was used as a normalizing factor to better quantify the mRNA of target genes. When the process was finished, a blue light transilluminator was used to view the results.

\section{Cell proliferation assay:}

The cells were trypsinized at indicated days and the percentage of viable cells was measured by counting cells, which were stained by acridine orange/propidium iodide, an apoptosis indicator, with the Luna-FL Dual Fluorescence Cell Counter (Logos Biosystems).

\section{- Results and Discussion \\ Genome wide analysis of copy number variation on lung cancer in lifelong non-smokers:}

As tobacco-smoking is the major cause of lung cancer, people oftentimes disregard other potential causes of cancer. ${ }^{9}$ In order to study the factors the contribute to lung cancer other than smoking, the differences in genetic alterations between smokers and lifetime non-smokers were compared. While analyzing, it was noted that several genes in chromosome $4 \mathrm{p} 11$ were deleted, which occurred in $6.31 \%$ of lifelong non-smokers and $0.2 \%$ of smokers. (Table 1) From the 8 types of genetic alterations presented in chromosome $4 \mathrm{p} 11$, we focused on Zygote Arrest 1 (ZAR1).

Table 1: Copy number deletion on lung cancer in lifelong non-smokers. Gene deletions were mainly found in chromosome 4p11 in lifelong nonsmokers.

\begin{tabular}{llllll}
\hline Gene & Cytoband & $\begin{array}{l}\text { Lifelong non-smoker } \\
(\mathrm{n=111)}\end{array}$ & $\begin{array}{l}\text { Smoker } \\
(\mathrm{n}=976)\end{array}$ & Log Ratio & P-value \\
\hline CWH43 & $4 \mathrm{p} 11$ & $7(6.31 \%)$ & $2(0.20 \%)$ & 4.94 & $2.938 \mathrm{e}-6$ \\
FRYL & $4 \mathrm{p} 11$ & $7(6.31 \%)$ & $2(0.20 \%)$ & 4.94 & $2.938 \mathrm{e}-6$ \\
OCIAD1 & $4 \mathrm{p} 11$ & $7(6.31 \%)$ & $2(0.20 \%)$ & 4.94 & $2.938 \mathrm{e}-6$ \\
OCIAD2 & $4 \mathrm{p} 11$ & $7(6.31 \%)$ & $2(0.20 \%)$ & 4.94 & $2.938 \mathrm{e}-6$ \\
SLAIN2 & $4 \mathrm{p} 11$ & $7(6.31 \%)$ & $2(0.20 \%)$ & 4.94 & $2.938 \mathrm{e}-6$ \\
SLC10A4 & $4 \mathrm{p} 11$ & $7(6.31 \%)$ & $2(0.20 \%)$ & 4.94 & $2.938 \mathrm{e}-6$ \\
TEC & $4 \mathrm{p} 11$ & $7(6.31 \%)$ & $2(0.20 \%)$ & 4.94 & $2.938 \mathrm{e}-6$ \\
ZAR1 & $4 \mathrm{P} 11$ & $7(6.31 \%)$ & $2(0.20 \%)$ & 4.94 & $2.938 \mathrm{e}-6$ \\
\hline
\end{tabular}

siRNA targeting ZAR1 decreases mRNA of ZAR1 on NCI-H358 lung cancer cells:

To find the effect of siRNA transfection on ZAR1 expression level, mRNA expression level was quantified using agarose gel electrophoresis. The band intensity shows the mRNA expression level of ZAR1 and GAPDH in three samples: the siControl, the siZAR1 (10 pmol), and the siZAR1 (20pmol). (Figure 1A) The siControl samples were transfected with non-targeting siRNA for non-specific effects related to siRNA delivery to provide a baseline for target gene silencing. Two different concentrations of siRNA targeting ZAR1 were tested: $10 \mathrm{pmol}$ and $20 \mathrm{pmol}$. The ZAR1 expression level was normalized with the expression level of GAPDH. (Figure 1B) Compared to the siControl, expression level of ZAR1 decreased to $30 \%$ in siZAR1 $(10 \mathrm{pmol})$ samples. When siZAR1 was treated with $20 \mathrm{pmol}$, the expression level of ZAR1 further decreased to $20 \%$. Since the lowest expression level of ZAR1 was achieved by the 20 pmol concentration of siRNA, we used 20 pmol condition for the downstream experiments to find the functional role of ZAR1 depletion on NCI-H358 cells.

ZAR1 depletion increases cell proliferation on NCI-H358 lung cancer cells:

Cancer cell proliferation is a process that results in an increase of the number of cells, which is defined by the balance between cell division and cell death. To find the functional role of ZAR1 in cancer cell proliferation, two samples were compared: siControl (negative control) and siZAR1 with 20 pmol. As shown in Figure 2, the cell number was measured after siRNA transfection in five different timelines: 0 hour, 24 hours, 48 hours, 72 hours, and 96 hours. The relative cell proliferation was quantified and the cell number of 0 hour was used to calculate the relative cell number increase. Even after 72 hours of transfection the cell number did not show a significant 
difference. However, at 96 hour, cell number was significantly increased in siZAR1 transfected cells. This result indicates that ZAR1 depletion induces NCI-H358 cells to proliferate.
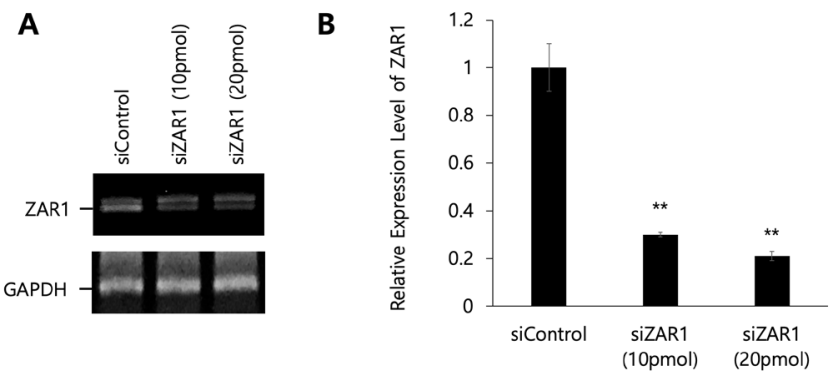

Figure 1: Effect of siRNA targeting ZAR1 on the mRNA expression level of ZAR1. (A) Gel electrophoresis analysis of ZAR1 and GAPDH PCR products. (B) Quantification of ZAR1 mRNA levels $48 \mathrm{~h}$ after transfection $(\mathrm{n}=3$, mean $\pm \mathrm{SD})$, student's t-test, ${ }^{* *} \mathrm{p}<0.01$. The sample with higher concentration of siRNA has significantly lower level of ZAR1 expression.

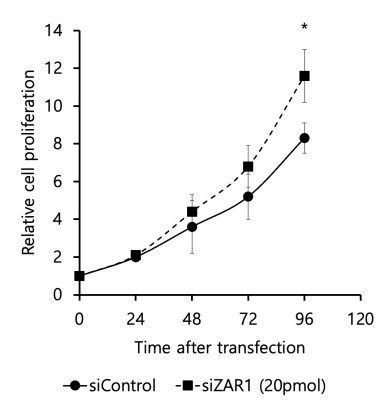

Figure 2: Effect of ZAR1 depletion on cell proliferation on NCI-H358 lung cancer cells. $(n=3$, mean $\pm S D)$, student's t-test, ${ }^{*} p<0.05$. The sample with siZAR1 transfected cells shows a greater level of cell proliferation than siControl transfected cells.

\section{Conclusions}

Copy number variation (CNV) is a phenomenon in which parts of genomes are repeated and the number of repeats on the genome varies between lung cancer patient groups-in this research the $\mathrm{CNV}$ difference between the lifelong nonsmokers and smokers was investigated. ${ }^{10} \mathrm{CNV}$ is a type of structural variation which is a type of duplication or deletion event that affects the base pairs in DNA. ${ }^{11}$ It was found that the copy number deletion is frequently observed in chromosome $4 \mathrm{p} 11$ in non-smoking lung cancer patients. At this chromosomal position, eight genes were deleted including ZAR1. A previous study has discovered that copy number deletion led to decreased gene expression, indicating that the loss of copy numbers in these genes may have low mRNA transcript levels. ${ }^{12}$ Since the focus of this research was only on the function of ZAR1 in lung cancer cells, a comparison study with the other seven genes should further be investigated in order to provide a comprehensive understanding about the overall impact of CNV in chromosome 4p11 on lung cancer development.

ZAR1 may have a positive effect on cell proliferation, but the question remains about how. $8 \mathrm{~A}$ cell cycle is a series of events that allows the growth and the division of a cell. ${ }^{13}$ Cell death, on the other hand, is an event in which a cell ceases to perform its functions mostly through apoptosis, programmed cell death. ${ }^{14}$ Since both cell cycle and cell death are closely related with cell proliferation, further study is needed to determine whether ZAR1 either regulates cell cycle or promotes cell death in lung cancer.

By silencing the expression level of ZAR1 in a lung cancer cell line with siRNA, this study has analyzed the possible role of ZAR1 in the development of lung cancer. The cell line in which the expression of ZAR1 was inhibited presented a greater rate of cell proliferation than in the control cell line. If the inhibition of ZAR1 promotes the development of lung cancer, it seems reasonable to infer that ZAR1, as suspected, is a potential cancer suppressor gene and therefore can be a promising target for a novel biomarker for lung cancer.

\section{Acknowledgements}

I would like to thank my supervisor Dr. Woo Rin Lee for his guidance and advice in this project.

\section{References}

1. Cersosimo, R. J., Lung cancer: a review. Am J Health Syst Pharm 2002, 59 (7), 611-42.

2. Torre, L. A.; Siegel, R. L.; Jemal, A., Lung Cancer Statistics. Adv Exp Med Biol 2016, 893, 1-19.

3. Lemjabbar-Alaoui, H.; Hassan, O. U.; Yang, Y.W.; Buchanan, P., Lung cancer: Biology and treatment options. Biochim Biophys Acta 2015, 1856 (2), 189-210.

4. Furrukh, M., Tobacco Smoking and Lung Cancer: Perceptionchanging facts. Sultan Qaboos Univ Med J 2013, 13 (3), 345-58.

5. Samet, J. M.; Avila-Tang, E.; Boffetta, P.; Hannan, L. M.; OlivoMarston, S.; Thun, M. J.; Rudin, C. M., Lung cancer in never smokers: clinical epidemiology and environmental risk factors. Clin Cancer Res 2009, 15 (18), 5626-45.

6. Cerami, E.; Gao,J.; Dogrusoz, U.; Gross, B. E.; Sumer, S. O.; Aksoy, B. A.; Jacobsen, A.; Byrne, C. J.; Heuer, M. L.; Larsson, E.; Antipin, Y.; Reva, B.; Goldberg, A. P.; Sander, C.; Schultz, N., The cBio cancer genomics portal: an open platform for exploring multidimensional cancer genomics data. Cancer Discov 2012, 2 (5), 401-4.

7. Wu, X.; Viveiros, M.M.; Eppig, J. J.; Bai, Y.; Fitzpatrick, S. L.; Matzuk, M. M., Zygote arrest 1 (Zar1) is a novel maternal-effect gene critical for the oocyte-to-embryo transition. Nat Genet 2003, 33 (2), 187-91.

8. Richter, A. M.; Kiehl, S.; Koger, N.; Breuer, J.; Stiewe, T.; Dammann, R. H., ZAR1 is a novel epigenetically inactivated tumour suppressor in lung cancer. Clin Epigenetics 2017, 9, 60.

9. Walser, T.; Cui, X.; Yanagawa, J.; Lee, J.M.; Heinrich, E.; Lee, G.; Sharma, S.; Dubinett, S. M., Smoking and lung cancer: the role of inflammation. Proc Am Thorac Soc 2008, 5 (8), 811-5.

10.Qiu, Z.W.; Bi, J. H.; Gazdar, A. F.; Song, K., Genome-wide copy number variation pattern analysis and a classification signature for non-small cell lung cancer. Genes Chromosomes Cancer 2017, 56 (7), 559-569.

11.Lauer, S.; Gresham, D., An evolving view of copy number variants. Curr Genet 2019, 65 (6), 1287-1295.

12.Shao, X.; Lv, N.; Liao, J.; Long, J.; Xue, R.; Ai, N.; Xu, D.; Fan, $\mathrm{X}$., Copy number variation is highly correlated with differential gene expression: a pan-cancer study. BMC Med Genet 2019, 20 (1), 175.

13.Schafer, K. A., The cell cycle: a review. Vet Pathol 1998, 35 (6), 461-78.

14.Elmore, S., Apoptosis: a review of programmed cell death. Toxicol Pathol 2007, 35 (4), 495-516. 
- Author

Jana Choe is a student of The Governor's Academy in Byfield, Massachusetts. She is interested in studying biology, biomedical research, and genetics, and is hoping to deepen her understanding in these areas of research in the future. 